\title{
KNOWLEDGE AND PRACTICE TOWARDS QUALITY USE OF MEDICINE AMONG UNDERGRADUATE STUDENTS
}

\author{
Wardah Mustafa Din ${ }^{1}$ and Noor Ashikeen Zainal Abidin ${ }^{2}$ \\ ${ }^{1}$ Pusat Citra Universiti, Universiti Kebangsaan Malaysia, 43600 UKM Bangi, Selangor, Malaysia. \\ 2 Pharmaceutical Division, Hospital Serdang, Jalan Puchong, 43000 Kajang, Selangor, Malaysia.
}

Corresponding author: Wardah Mustafa Din

Email: wardahmustafadin@ukm.edu.my

\begin{abstract}
Quality use of medicine is crucial not only to optimize health resources, but to safeguard consumers from unsafe use of medicine. Knowing Your Medicine (KYM) Campaign was launched by the Ministry of Health (MOH) Malaysia as an initiative to raise awareness to consumers on quality use of medicines in ensuring wise, safe and effective use of medicines. Materials of the campaign which is the KYM Module, is integrated in one of the elective course in UKM which is offered to undergraduate students across different faculties to increase knowledge and practice on quality use of medicine. This study aims to identify the impact of the KYM Module towards knowledge and practice of the undergraduates enrolled into the course. A one group pre and post-test research design was employed to students using purposive sampling $(n=62)$. The questionnaire consists of three sections which are i) demographic profile, ii) knowledge assessment (14 items) and iii) practice assessment (15 items). Frequency analysis and paired sample $T$-test were used to measure the impact of the module. Knowledge of the undergraduates increased from fair/good to good/excellent, as knowledge score of $64.5 \%$ students reached excellent post-test compared to $35.5 \%$ pre-test. In terms of practice, a paired T-test analysis shows that there is a statistically significant increase in practice scores from pre-test $(M=4.2, S D=.472)$ to post-test $(M=4.57, S D=.341), t(61)=-3.859, p<.05$ (two tailed). In summary, both knowledge and practice improved significantly among undergraduates after completing the module. This research serves as an important data to support the effectiveness of $\mathrm{MOH}$ initiative in disseminating important information regarding quality use of medicine to the public.
\end{abstract}

Keywords: Quality use of medicine, knowledge, practice, impact, module effectiveness

\section{INTRODUCTION}

Quality use of medicines among public consumers could still be improved in Malaysia as reported in The National Survey on the Use of Medicine 2015,13. Compliance towards prescribed medicine is still a problem, whereby $73.1 \%$ of the respondents were declared as noncompliant as they admit forgotten to take their prescribed medication. The survey also showcased that only $67.7 \%$ of consumers have the knowledge about proper storage and disposal of medicine. Correct and proper use of medicine, not only safeguard consumers from the dangers of unsafe use of medicine, but also optimise health resources economically. Example of irrational medicine use among consumers are improper patients' adherence to dosing schedules and treatment regimens, inappropriate self-medication and inappropriate selection of medicines without consideration for costeffectiveness and efficacy. Among many factors that contributes to irrational medicine use is uninformed patient ${ }^{2}$. According to NSUM 2015, "Quality Use of Medicines (QUM)" is defined as "patients receive medications appropriate to their clinical needs, in doses that meet their own individual requirements for an adequate period of time, and the lowest cost to them and their community"'. World Health Organization (WHO) uses the same definition for rational use of drugs $^{3}$.

Since 2007, MOH through the Pharmaceutical Services Program launched the KYM Campaign. The objective of the initiative is to raise awareness to consumers on QUM in ensuring wise, safe and effective use of medicines by the consumers. The campaign since then have evolved to many approaches, with the current approach since 2012, is through the appointments of ambassadors among the public community. KYM Ambassador Program purpose is to empower the community towards rational use of medicines. The program targets to provide the public with information regarding issues concerning medicines and health thus encourage behavioral changes. Ambassadors are appointed either from volunteer individuals among the public community or selected based on recommendation. A structured training program is conducted to coach the ambassadors on basic information of QUM. The program utilizes peer education and behavioral change approach in ensuring effective dissemination of information. Through the training, ambassadors are able to understand and share basic information regarding QUM to the community, together with healthcare professionals and pharmacists. Even though the campaign has been implemented for more than 10 years, majority of the public is still 
unaware of the campaign and thus, participation rate to related activities are still very low ${ }^{1}$.

To support the dissemination of the quality use of medicine to undergraduate students, the KYM module materials from the campaign are integrated into an elective course offered by Pusat Citra Universiti, Universiti Kebangsaan Malaysia. The coordinator for the course in UKM is currently being appointed as one of the KYM ambassador under Serdang Hospital, Selangor. The elective course offered is LMCR1572 Benefits and Risks of Natural Products, and is open for enrolment to all undergraduates from different faculties. The materials of the KYM campaign are integrated directly into the course content by means of conventional lecture sessions, sharing from invited pharmacists, group discussions and group projects for a duration of 14 weeks.

The aim of integrating the KYM module in the elective course is to increase the level of basic QUM knowledge and instil proper practice among undergraduates, as consumers. This is consistent with the KYM campaign objective which is to provide the public with information regarding QUM and thus encourage behavioural change. According to NSUM 2015, 60.2\% of youths aged 18-27 in Malaysia have basic understanding of medicine and $77.7 \%$ understand the proper use of medicine. However, a more specific research among students in University Sains Malaysia (USM) shows an alarming $70 \%$ students, only have limited information about correct medicine use ${ }^{4}$. There are few studies done on knowledge and practice among undergraduates towards antibiotic use ${ }^{5}$ which also displays minimal knowledge and inappropriate practice of antibiotics. Hence, this study aims to assess the impact of embedding the KYM module materials into an elective university course, in regards to the level of knowledge and practice among undergraduates in UKM. The findings will give important insights in understanding the effectiveness of the KYM campaign modules and thus, might be helpful in suggesting improvement to the campaign content in future and be embedded in other selected courses as well.

\section{METHODS}

\section{Research Design and Sampling}

A one group pre-posttest design was adopted for the study. One group pre posttest design is part of a quasi-experimental research design, which utilizes a single group of research participants. Data were collected before and after an intervention. Impact of the intervention is measured by significant difference of the pre and post scores. Participants of the study were students enrolled into the elective course (LMCR1572 Benefits and Risks of Natural Products) in the second semester of 2019/2020 academic year. Students responses on their knowledge and practices were measured via an online survey in Google Form. The pre-test survey was collected during the first week of the semester and the Post-test survey was done in week-14 which is the final week of the semester. To make sure only enrolled students of the course participate in the survey, the link to the survey is posted in the Learning Management System of the University, which only permits enrolled students to the course contents, including the survey link. The study was conducted at Universiti Kebangsaan Malaysia. All 62 students enrolled into the course participated in the survey. Students enrolled into the course consists of students from various faculties and programs as the elective course were offered to all undergraduates, and any of them are free to choose the courses that they prefer.

\section{Research Instrument}

A self-developed questionnaire was employed to the participants of the study online via Google Form. Link to the questionnaire were given to the students through UKM Learning Management System during lecture in Week-1(Pre-test survey) and in Week-14 (Post-test survey). The link can only be assessed by students that is enrolled into the course. Email address and student registration number is recorded in the questionnaire submission. Students were given 10 minutes to answer all the question in class, without any discussion among any of them. All students submitted the online survey right after the allocated time that were given in class. The survey consists of three sections namely; demographic profile of the respondents, knowledge assessment and practice assessments. The details of respondents' demographic profile include gender, faculty, ethnic and religion. The knowledge assessment consists of 14 statements which covers all the main points of the KYM course content. Only two answer options were given for each statement which are 'True' and 'False'. Whereas, practice was measured by 15 items with a Likert scale of 1 to 5 (1: Strongly disagree and 5: Strongly agree). The items cover practice regarding product registration, consumption, storage and disposal of medications as structured in the KYM campaign materials. A Cronbach alpha value were calculated for all the 15 items for practice to see the internal reliability of the items used to measure 'practice' in the questionnaire. The Cronbach alpha value was .862 for all the 15 items, thus all items are reliable for measuring 'practice'.

\section{Intervention Procedure}

The KYM module were integrated into an elective course LMCR1572 Benefits and Risks of Natural Products. The elective course is a two credit course, which includes 2 hours' class every week for the whole 14-week semester. The materials of KYM campaign from $\mathrm{MOH}$ consist of infographics, videos, Power Point slides and a 
'Meditips' booklet guide and are embedded in the course content. The content of the module can be divided to four main sections which are 1) Introduction to medicine, 2) Product registration, 3) Quality practices of consumption and 4) Quality practices of storage and disposal. In the section of quality practices of consumption, the concept of $5 R$ is being introduced i.e., Right patient, Right medicine, Right dose, Right route of administration and Right time of administration.

Throughout the semester, the KYM materials are integrated into the other course contents by five different means of teaching and learning which are formal lectures, sharing from pharmacists, group discussions, group project and self- reflection writing. The course plan throughout the 14 weeks are as tabulated in Table 1 . Besides topics regarding the KYM content, there are other topics that are covered in the course i.e., introduction to natural products, source of natural products, benefits and risks of natural products, understanding bioactive ingredients in natural based health products and safety precautions in consuming natural products. For this specific cohort of students, the group project comprises of an innovation project from the KYM materials, to invent a new approach to the materials for dissemination of KYM content to two different audiences which are primary school children and university students.

Table 1. The course plan for 14 weeks

\begin{tabular}{ll}
\hline Week & Approach \\
\hline 1 & Introduction to course \\
$2-4$ & (Pre-test survey) \\
$5-6$ & Lecture \\
7 & Project group discussions \\
$8-10$ & Sharing from pharmacist \\
$11-12$ & Project group execution \\
13 & Group presentation \\
14 & Reflective writing \\
& Course wrap-up \\
\hline
\end{tabular}

\section{Data Analysis}

Data were analyzed using the Statistical Package for Social Sciences (SPSS) version 24.0. Descriptive analysis was computed to showcase the demographic profiling of the participants. The level of knowledge was calculated by means of frequency analysis of correctly answered statements (Full score is 14/14). A score scale was developed to differentiate the level of knowledge which are excellent $(12-14)$, good (912), fair (5-8) and poor (0-4). Impact of the intervention were assessed by comparing the frequency of scores for each level of knowledge between the pre and post-test scores. Practice was measured with a 5-point Likert scale and the skewness and kurtosis values were calculated to see whether the data is normally distributed. Items to assess practice were in a form of statements with a 5 -scale Likert options.

Respondents were asked to self-rate each statement according to their individual practice regarding medicine use. Mean average of each statements were calculated and skewness and kurtosis were calculated to identify the distribution. The skewness value indicates normal distribution is between -3 and 3 while kurtosis value is in between -1 and 1 . The skewness and kurtosis value of mean score for pre-test data are -.513 and -.534 while the value of skewness and kurtosis for post-test mean score are -.694 and -.208. Thus, mean score for practice in both pre-test and post-test can concluded as normally distributed. Upon confirmation of the normal distribution data sets, a paired sample T-test were performed on the pre and post mean scores to assess the significant difference.

\section{RESULTS}

\section{Demographic Profiling of Respondents}

For this study, all of the 62 respondents were undergraduate students of LMCR1572 elective course for the 2018/2019 academic year at Universiti Kebangsaan Malaysia. Out of the 62 respondents, $59.7 \%(n=37)$ are female students. Majority of the students were from the Faculty of Islamic Studies (48.4\%). Other faculties recorded were Social Science and Humanities (16.1\%), Science and Technology (14.5\%), Liberal Studies (11.3\%) and both Economy and Management and Education with 4.8\% students' enrolment in the course. Majority of the students are Muslim (59\%) and from Malay ethnic (59\%). Other demographic statistics are as shown in Table 2. 
Table 2. Demography profile of respondents

\begin{tabular}{llcc}
\hline Items & & Frequency & $\%$ \\
\hline Gender & Male & 25 & 40.3 \\
& Female & 37 & 59.7 \\
Faculty & Total & 62 & 100.0 \\
& Liberal Studies & 7 & 11.3 \\
& Social Science \& Humanities & 10 & 16.1 \\
& Science \& Technology & 9 & 14.5 \\
& Islamic Studies & 30 & 48.4 \\
Ethnic & Economy \& Management & 3 & 4.8 \\
& Education & 3 & 4.8 \\
& Total & 62 & 100.0 \\
& Malay & 59 & 95.2 \\
Religion & Chinese & 1 & 1.6 \\
& Indian & 1 & 1.6 \\
& Others & 1 & 1.6 \\
& Total & 62 & 100.0 \\
& Islam & 59 & 95.2 \\
& Hindu & 1 & 1.6 \\
& Buddha & 1 & 1.6 \\
& Others & 1 & 1.6 \\
\end{tabular}

Impact of Module on Knowledge

Students were asked to answer fourteen (14) 'True' and 'False' statements to assess the level of knowledge. Statements were important points from the KYM module. Answers were scored for each student with full score of 14/14. A score scale was developed to differentiate the level of knowledge which are excellent (12-14), good (912), fair (5-8) and poor (0-4). From the analysis, it is showed that students which obtains excellent score (12-14 score) increased from $35.5 \%$ to $64.5 \%$ and students with a fair score of knowledge decreased to only two students in the post-test score.

Table 3. Level of knowledge according to score

\begin{tabular}{lcccc}
\hline Level of Knowledge & Pre Test & \multicolumn{2}{c}{ Post Test } \\
\cline { 2 - 5 } & $\mathrm{N}$ & $\%$ & $\mathrm{~N}$ & $\%$ \\
\hline Excellent & 22 & 35.5 & 40 & 64.5 \\
Good & 33 & 53.2 & 20 & 32.3 \\
Fair & 7 & 11.3 & 2 & 3.2 \\
Poor & 0 & 0 & 0 & 0 \\
Total & 62 & 100.0 & 62 & 100 \\
\hline
\end{tabular}

From the statements in the questionnaire, there are two statements that all $100 \%$ students answered correctly, even before the intervention. This shows that the baseline level of some knowledge area is good, even before the intervention. The questions are regarding registration of medicine and the right dosing of medicine. Among all of the knowledge

statements asked, five statements were observed with a high percentage of knowledge score increment. The five statements are about the right timing of administration (S4), medicine labeling (S5), medicine storage (S6), medicine disposal (S11), and natural products use (S12). Analysis of each statements are as recorded in Table 4.

\section{Impact of Module on Practice}

A paired sample T-test was conducted to the pre and post-test data, to evaluate the impact of the KYM modules towards practice of quality medicine use among students. There was a statistically significant increase in practice

scores from pre-test $($ Mean $=4.2, \mathrm{SD}=.472)$ to post-test $($ Mean $=4.57, \mathrm{SD}=.341), \mathrm{t}(61)=-$ $3.859, p<.05$ (two tailed). The mean increase in practice mean score is 0.30 with a $95 \%$ confidence interval ranging from -.457 and -.145. The eta squared statistic (.196) indicated a large effect size. Results are tabulated in Table 5. 
Table 4. Frequency of students correctly answered each knowledge statements and the difference

\begin{tabular}{|c|c|c|c|c|c|c|c|}
\hline \multirow{2}{*}{ No. } & \multirow{2}{*}{ Statements } & \multicolumn{2}{|c|}{ Pre Test } & \multicolumn{2}{|c|}{ Post Test } & \multicolumn{2}{|c|}{ Difference } \\
\hline & & $\mathbf{N}$ & $\%$ & $\mathbf{N}$ & $\%$ & $\mathbf{N}$ & $\%$ \\
\hline 1 & $\begin{array}{l}\text { All medicine should be registered under the Ministry of } \\
\text { Health }(\mathrm{MOH})\end{array}$ & 62 & 100.0 & 62 & 100.0 & 0 & 0 \\
\hline 2 & $\begin{array}{l}\text { Herbal based health products does not need to be } \\
\text { registered }\end{array}$ & 58 & 93.5 & 56 & 90.3 & -2 & -3.5 \\
\hline 3 & $\begin{array}{l}\text { The right does of medicine is important to ensure the } \\
\text { efficacy of the medicine }\end{array}$ & 62 & 100.0 & 62 & 100.0 & 0 & 0 \\
\hline 4 & $\begin{array}{l}\text { The right time for consumption of medicine is directly } \\
\text { after a meal }\end{array}$ & 16 & 25.8 & 33 & 53.2 & 17 & +27.4 \\
\hline 5 & $\begin{array}{l}\text { Labels on the medicine contains name of medicine, } \\
\text { dose, timing and price. }\end{array}$ & 28 & 45.2 & 44 & 71.0 & 16 & +25.8 \\
\hline 6 & All medicines should be kept inside the refrigerator & 37 & 59.7 & 54 & 87.1 & 17 & +27.4 \\
\hline 7 & Medicine can't be stored in a high temperature place & 54 & 87.1 & 59 & 95.2 & 5 & +8.1 \\
\hline 8 & All types of medicine can be bought at the pharmacy & 40 & 64.5 & 41 & 66.1 & 1 & +1.6 \\
\hline 9 & $\begin{array}{l}\text { If you forget to take your medicine, you need to take } \\
\text { double the dose when you remember }\end{array}$ & 61 & 98.4 & 61 & 98.4 & 0 & 0 \\
\hline 10 & $\begin{array}{l}\text { All natural based health products are safe to be } \\
\text { consumed }\end{array}$ & 52 & 83.9 & 51 & 82.3 & 1 & +1.6 \\
\hline 11 & Unfinished medicine should be thrown down the sink & 50 & 80.6 & 61 & 98.4 & 11 & +17.8 \\
\hline 12 & $\begin{array}{l}\text { Natural herbal based products can be used as a } \\
\text { substitute to prescribed medicine }\end{array}$ & 33 & 53.2 & 47 & 75.8 & 14 & +22.6 \\
\hline 13 & $\begin{array}{l}\text { Ingredients of medicine and herbal based products } \\
\text { should be checked before consumption }\end{array}$ & 62 & 100.0 & 60 & 96.8 & -2 & -3.2 \\
\hline 14 & Everyone can consume natural based health products & 50 & 80.6 & 52 & 83.9 & 2 & +3.2 \\
\hline
\end{tabular}

Table 5. Mean average scores for each items Pre and Post-test

\begin{tabular}{|c|c|c|c|c|c|c|}
\hline \multirow{2}{*}{ No. } & \multirow{2}{*}{ Statements } & \multicolumn{3}{|c|}{ Pre Test } & \multicolumn{2}{|c|}{ Post Test } \\
\hline & & $\mathbf{N}$ & Mean & S.D & Mean & S.D \\
\hline 1 & $\begin{array}{l}\text { I always make sure the medicine that I buy is registered with the } \\
\text { Ministry of Health }(\mathrm{MOH})\end{array}$ & 62 & 4.69 & .531 & 4.84 & .371 \\
\hline 2 & $\begin{array}{l}\text { I use traditional herbal medicine because of its safety and } \\
\text { efficacy }\end{array}$ & 62 & 3.50 & .763 & 3.50 & 1.067 \\
\hline 3 & $\begin{array}{l}\text { I always check the label of the medicine which is prescribed to } \\
\text { me }\end{array}$ & 62 & 4.63 & .579 & 4.73 & .485 \\
\hline 4 & $\begin{array}{l}\text { I always take my medications at the right timing as prescribed by } \\
\text { the doctor }\end{array}$ & 62 & 4.56 & .532 & 4.66 & .510 \\
\hline 5 & $\begin{array}{l}\text { I always take my medications according to the dose that is } \\
\text { prescribed by the doctor }\end{array}$ & 62 & 4.71 & .492 & 4.82 & .426 \\
\hline 6 & $\begin{array}{l}\text { If I am prescribed a medicine with dosing of twice a day, I will } \\
\text { take the medicine every } 12 \text { hours }\end{array}$ & 62 & 3.63 & 1.204 & 4.42 & .984 \\
\hline 7 & $\begin{array}{l}\text { I store my medicine according to the suggestions of the } \\
\text { pharmacists }\end{array}$ & 62 & 4.44 & .668 & 4.76 & .432 \\
\hline 8 & $\begin{array}{l}\text { I always check for the expiry date, the smell and the color of the } \\
\text { medicine before I consume it }\end{array}$ & 62 & 4.60 & .664 & 4.90 & .298 \\
\hline 9 & $\begin{array}{l}\text { I always refer back to a doctor/pharmacists if I have enquiries } \\
\text { regarding my medicine }\end{array}$ & 62 & 4.40 & .799 & 4.69 & .531 \\
\hline 10 & $\begin{array}{l}\text { I always dispose of unused/unfinished medicine by returning it } \\
\text { back at the pharmacy counter nearest to me }\end{array}$ & 62 & 3.50 & 1.352 & 4.35 & .960 \\
\hline 11 & $\begin{array}{l}\text { I always check the ingredients to any herbal based health } \\
\text { products that I use }\end{array}$ & 61 & 4.08 & .900 & 4.55 & .694 \\
\hline 12 & $\begin{array}{l}\text { I always make sure that the natural based products that I use are } \\
\text { registered with } \mathrm{MOH}\end{array}$ & 62 & 4.48 & .646 & 4.73 & .485 \\
\hline 13 & $\begin{array}{l}\text { I always consume the medicine prescribed by the doctor even } \\
\text { though I take other herbal health products }\end{array}$ & 62 & 3.87 & 1.000 & 4.21 & .926 \\
\hline 14 & $\begin{array}{l}\text { I always check the ingredients to any herbal base health products } \\
\text { that I buy }\end{array}$ & 62 & 4.44 & .760 & 4.65 & .630 \\
\hline 15 & $\begin{array}{l}\text { I never trust the testimonial of consumers as the only reference } \\
\text { before purchasing a health product }\end{array}$ & 62 & 4.52 & .695 & 4.76 & .432 \\
\hline
\end{tabular}




\section{DISCUSSION}

One of the knowledge item that shows improvement after the intervention, is the right time of medicine consumption. In the KYM module material, the $5 \mathrm{R}$ quality use of medicine

advocate participants on the right timing of medicine administration and the right medicine regime. Patients low adherence to medicine regime is similarly reported in Abdo-Rabbo et al. ${ }^{7}$ and among the preditors to low adherence is the level of knowledge of the specific item. In Malaysia, the NSUM survey 2015 recorded that $73.1 \%$ of Malaysians were non-compliant towards a medicine regime. Irrational administration of medicine may affect the efficacy of the medicine pose a serious threat to health ${ }^{2}$. Although it is shown that undergraduates have better knowledge regarding quality use of medicine, in line with a study in Penang, states that among predictors of good knowledge of medicine use is having a higher education in college/university ${ }^{6}$, but it doesn't cover all aspects of quality use.

Besides that, among important items that is siginificantly improved after the intervention, were knowledge on storage and disposal of medicines. Both of this information are to be provided by pharmacists and medical doctors to patients when prescribed. Inadequate knowledge on proper storage and disposal of medicine among students were reported in a study in India, whereby most students store their medicine in improper places such as the kitchen, bathroom and bedroom ${ }^{8}$. In this study, majority of the students dispose of unfinished medicine in the dustbin ${ }^{8}$. Similarly, in Kenya, consumers prefer to dispose medicine in the dustbin or flush it down the toilet, and some consumers prefer to keep it in the household to be shared with other nearby families ${ }^{9}$. Consumers were also reported to be unaware of the consequences of leftover medications and improper disposal of medications ${ }^{10}$. Improper storage of medications reduces the efficacy of the active ingredients and could also be misused by other members in the house. Substantial risk to the community and environment could occur if improper disposal of medications is not being addressed. In 2010, the Pharmaceutical Services Division, Ministry of Health Malaysia $(\mathrm{MOH})$ have implemented the Return Your Medicines Program. Through this program, patients can return their unused or excess medicines kept at home for safe disposal by $\mathrm{MOH}$. The KYM module is effective in improving knowledge among participants especially regarding the concept of $5 R$, storage and disposal of medications. Information on the MOH initiative 'Return Your Medicines Program' should be promoted actively to the consumers to prevent improper disposal of medications.
Many studies have proven the significance of knowledge towards effective consumer behavior $^{11}$ and human decisions ${ }^{12}$. Theory of Planned Behavior implies that attitude and belief are sculptured by knowledge. Both awareness and knowledge are two main factors affecting consumer behavior ${ }^{11}$. The same theory might apply to consumer behavior towards quality use of medicines, where knowledge of the quality use affects their practice. In a study regarding knowledge from Mc Earchern and Warnaby ${ }^{12}$, knowledge is categorized to three categories which are systems knowledge, action-related knowledge and effective knowledge. With regards to assessing the knowledge of students in this study, knowledge regarding quality use of medicine falls in two of the category which are action-related knowledge and effective knowledge. Both knowledge domains are crucial in affecting quality practice of medicines among consumers.

Coherent with the findings of knowledge impact as reported in the previous section, self-assessed practice among undergraduates also improved significantly in 14 out of 15 items being studied. The same areas as knowledge impacts were observed, practice also were observed improving, especially regarding the correct dosing and timing of medicine administration and disposal of unused medications. Compliance of consumers towards prescribed medicine is low in Malaysia as reported in NSUM $2015^{1}$ and even towards nutritional supplements ${ }^{13}$. Many studies have been executed on compliance issue of patients and consumers. Myriad of factors that contributes to non-compliance of consumers towards prescribed medicines and are categorized to patient-centered factors, therapy-related factors, social and economic factors, healthcare system factors, and disease factors ${ }^{14}$. Among chronic ill patients, compliance is due to complex medication regime and pill burden ${ }^{15}$. Regarding disposal of medicine, a study among Malaysian consumers highlighted a correlation between lack of knowledge with improper disposal of unused medications and suggested that the 'Return Your Medicine' campaign should be actively promoted ${ }^{16}$.

Among the items asked in the survey are safe use of herbal health products. One sub-topic included inside the KYM module is about the registration and safety of natural based health products. This is also covered widely in the elective course of LMCR1572. Findings demonstrates that practice among undergraduates also increased as shown in statement 11, 13 and 14. In the survey, practice among undergraduates to check the ingredients to herbal health products before usage increased, as well as checking the ingredients before purchase of these product. Previous studies have concluded that antecedents of actual purchase of consumers towards herbal 
health products are attitude, product safety and culture beliefs among others ${ }^{17}$. Another statement (S13) asked in the survey regarding herbal health product, is whether consumer always consume prescribed medicine even tough taking other herbal health products. Results show significant improvement in safe use of natural products after the course. Research on belief and attitude on complementary alternative medicine (CAM), which includes herbal health products, highlights that belief has positive correlation with attitude. the stronger the belief in CAM, the more positive the attitude toward $\mathrm{CAM}^{18}$. Effective promotion and education are important initiatives for quality use of medicine and it is pivotal to develop a strategy such that the promotion and programs are targeted and coordinated well ${ }^{19}$. A comprehensive review of the Malaysian healthcare and challenges of quality use of medicine, highlights that quality use of medicine is one of the problem that should be addressed strategically to strengthen Malaysia healthcare system $^{19}$. Holistic initiatives should include all stakeholders including non-government organizations (NGO), private agencies and also the community.

However, some limitations should be noted. First, this study uses purposive sampling to students of one elective course, one university in Malaysia. Second, is the small sample size of the study due to the limitations of the university registration system for the elective course. Hence, results and discussions might only serve to explain the knowledge and practice of this group of students only, and could not be generalized to other populations.

\section{CONCLUSION}

Practice of quality use of medicine still can be improved in Malaysia as many issues regarding it still arises such as non-compliance, self-assessed use of medicines, storage and disposal issues of medications (NSUM 2015). Hence, initiatives such as the KYM Campaign and module materials are important to be actively promoted to the society. From this study, it is proven that embedding the module into an elective course in the university, successfully increase knowledge and improve practice of undergraduate students pertaining quality and safe use of medicine. To make it accessible to other niche of the community, it would be effective to embed the KYM Campaigns into other formal based community activities such as Annual General Meetings of any society or through any other formal gathering. It can also be incorporated to any formal or informal trainings in corporate and private companies. The content material of the campaign is effective, but more initiatives at grass root level should be done to promote the campaign and module materials to different sector of the community.

\section{Acknowledgement}

Acknowledgement to Pharmacy Division of Serdang Hospital in providing assistance and materials regarding the KYM Module.

\section{REFERENCES}

1. Mohamad Azmi H, Fahad S, Mohd Dziehan $M$, et al. A national survey on the use of medicines (NSUM) by Malaysian consumers. Pharmaceutical Services Division, Ministry of Health Malaysia. 2016.

2. Ofori-Asenso R, Agyeman AA. Irrational use of medicines-a summary of key concepts. Pharmacy. 2016 Dec;4(4):35.

3. World Health Organization. Rational use of drugs: A review of major issues. In Proceedings of the Conference of Experts, Nairobi, Kenya, 22-29 November 1985.

4. Verma AK. Assessment of Pattern, Practice And Wastage of Medicine-Use Among Undergraduate Students of Universiti Sains Malaysia (Doctoral dissertation, Universiti Sains Malaysia).

5. Haque M, Rahman NA, McKimm J, et al. A cross-sectional study evaluating the knowledge and beliefs about, and the use of antibiotics amongst Malaysian university students. Expert review of anti-infective therapy. 2019 Apr 3;17(4):275-84.

6. Dawood OT, Hassali MA, Saleem F. Factors affecting knowledge and practice of medicine use among the general public in the State of Penang, Malaysia. Journal of Pharmaceutical Health Services Research. 2017 Mar;8(1):51-7.

7. Abdo-Rabbo A, Al-Ansari M, Gunn BC, et al. The use of medicines in Oman: Public knowledge, attitudes and practices. Sultan Qaboos University Medical Journal. 2009 Aug;9(2):124.

8. Pankajkumar PD, Chacko S, Prakashkumar BS. Storage and Disposal of Medicines In Home Among Students. Journal of Pharmacy Research. 2016 Jun; 10(6):343-50.

9. Angi'enda SA, Bukachi SA. Household knowledge and perceptions on disposal practices of unused medicines in Kenya. J Anthropol Archaeol. 2016 Dec;4(2):120. 
10. Rani NV, Thennarasu $P$, Keerthana $M$, et al. Assessment of Knowledge and Awareness on the Disposal of Expired and Unused Medicines among Medication Consumers. Journal of Young Pharmacists. 2019 Oct 1;11(4).

11. Ishak S, Zabil NF. Impact of consumer awareness and knowledge to consumer effective behavior. Asian Social Science. 2012 Nov 1;8(13):108.

12. McEachern MG, Warnaby G. Exploring the relationship between consumer knowledge and purchase behaviour of value-based labels. International Journal of Consumer Studies. 2008 Sep;32(5):414-26.

13. Ching AL, Zulkifli NS, Akmar SN, et al. Factors Affecting Compliance Rate towards Oral Nutritional Supplements Intake among Geriatric Patients in Hospital Kuala Lumpur. Jurnal Sains Kesihatan Malaysia (Malaysian Journal of Health Sciences). 2018 Dec 31;17(1).

14. Jin J, Sklar GE, Oh VM, Li SC. Factors affecting therapeutic compliance: A review from the patient's perspective. Therapeutics and clinical risk management. 2008 Feb;4(1):269.

15. Islahudin F, Hasan SZ. Medication Adherence and Satisfaction among Patients in Malaysia. Research Journal of
Pharmacy and Technology. 2019;12(3):1051-4.

16. Ong SC, Ooi GS, Shafie AA, et al. Knowledge, attitude and disposing practice of unused and expired medicines among the general public in Malaysia. Journal of Pharmaceutical Health Services Research. 2020 Jun;11(2):141-8.

17. Ismail S, Mokhtar SS. Linking attitude to actual purchase of herbal product in Malaysia: The moderating role of perceived risk. Journal of Asian Business Strategy. 2016 Feb 1;6(2):22.

18. Islahudin F, Shahdan IA, MohamadSamuri S. Association between belief and attitude toward preference of complementary alternative medicine use. Patient preference and adherence. 2017;11:913-918.

19. Mohd-Tahir NA, Paraidathathu T, Li SC. Quality use of medicine in a developing economy: Measures to overcome challenges in the Malaysian healthcare system. SAGE Open Medicine. 2015 Jul 21;3:1-8. 